\title{
Fabrication of plastic microlens array using gas-assisted micro-hot-embossing with a silicon mold
}

\author{
C.-Y. Chang ${ }^{\text {a }}$, S.-Y. Yang ${ }^{\text {a,* }}$, L.-S. Huang ${ }^{b}$, J.-H. Chang ${ }^{a}$ \\ a Department of Mechanical Engineering, National Taiwan University, Taipei 106, Taiwan \\ ${ }^{\mathrm{b}}$ Institute of Applied Mechanics, National Taiwan University, Taipei 106, Taiwan
}

Received 3 May 2005

Available online 29 November 2005

\begin{abstract}
This paper reports an innovative method for fabrication of plastic microlens arrays. By using gas pressure to press the plastic film onto silicon mold of holes array, microlens array can be directly fabricated. A machine with closed chamber for gas-assisted micro-hot-embossing was constructed and tested. The $300 \times 300$ plastic microlens array with a diameter of $150 \mu \mathrm{m}$ and a pitch of $200 \mu \mathrm{m}$ were successfully produced. Under the condition of $150{ }^{\circ} \mathrm{C}, 10-40 \mathrm{kgf} / \mathrm{cm}^{2}$ gas pressure and 30-90 s duration, the microlens with uniform and strong focusing function were formed on the polycarbonate film. The shape and height of microlens can be changed by adjusting the processing temperature, pressure and duration. This technique shows great potential for fabricating microlens array on large plastic films with high productivity and low cost. (c) 2005 Elsevier B.V. All rights reserved.
\end{abstract}

Keywords: Gas-assisted micro-hot-embossing; Hot embossing; Deep reactive ion etching; Replication; Silicon mold; Microlens array

\section{Introduction}

In recent years interest has grown in fabrication of microlens arrays due to their wide applications in optical computing, optical signal processing, optical interconnection, optical data storage, display, etc. Many methods for fabricating microlens array have been proposed and demonstrated, such as thermal reflow [1-3], excimer laser ablation [4], gray scale photolithography [5], microjet fabrication [6], hot embossing of plastic material on a lens array mold made by focused ion beam milling [7] and

\footnotetext{
* Corresponding author. Fax: +886283695574.

E-mail address: syyang@ntu.edu.tw (S.-Y. Yang).
}

hot intrusion process [8]. Among them, Most are expensive and not easily accessible to scientists and industrialists. Although the thermal reflow technique is regarded as a low cost mass-production process, the reflow of photoresist is difficult to control to yield precise shape.

The conventional hot embossing [7] and hot intrusion process [8] are comparatively inexpensive, but there are inherent problems due to the pressing mechanism using hot plates of press. The pressure between the mold and plastic substrate is higher in the center and lower in the edge. The pressure distribution is not uniform. The embossing area is thus limited. Besides, the mold material is limited to metal. Glass or silicon molds are often too brittle to be pressed by hot plates. 
In order to overcome the problem, we developed an innovative method using gas to exert isotropic pressure for micro-hot-embossing. Perfectly uniform embossing pressure throughout the whole area can be achieved. In addition, silicon molds can be used.

In this study, gas-assisted micro-hot-embossing is used to fabricate plastic microlens array. A silicon mold with holes array microstructures is first fabri- cated by conventional photolithography and deep reactive ion etching process. Plastic film is then placed on top of the mold, and the stack is placed in the closed chamber. Upon heating above the glass transition temperature $\left(T_{\mathrm{g}}\right)$ of the plastic film, nitrogen gas is introduced into the chamber. Under gas pressure, the polymer material is partially filled into the circular holes, and a convex surface is formed due to viscoelastic deformation and surface tension.

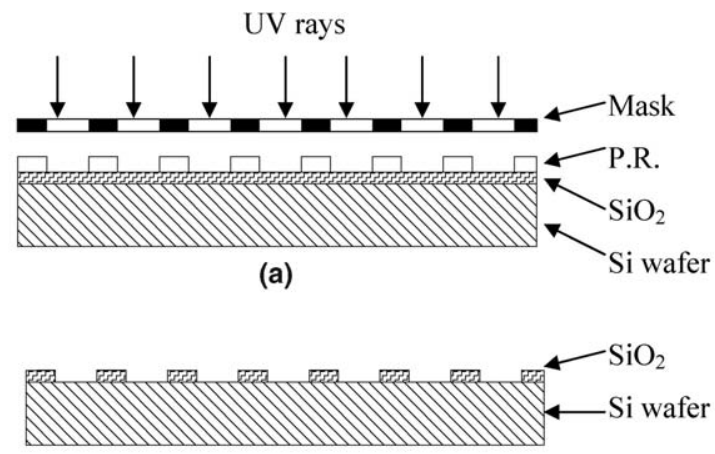

(b)

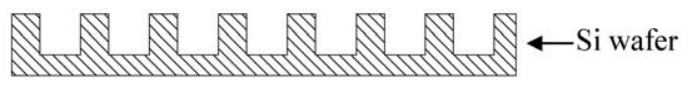

(c)

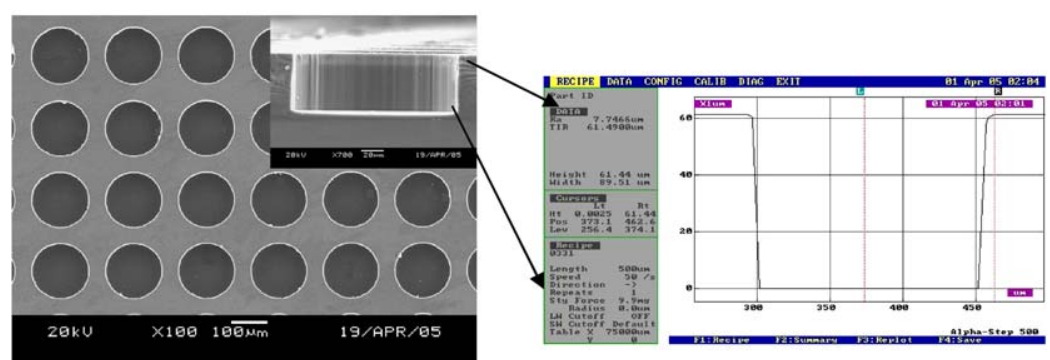

(d)

Fig. 1. Procedures for fabricating silicon holes array mold. (a) Photolithography, (b) mask etching, (c) silicon etching and (d) SEM image and surface profile of silicon mold.

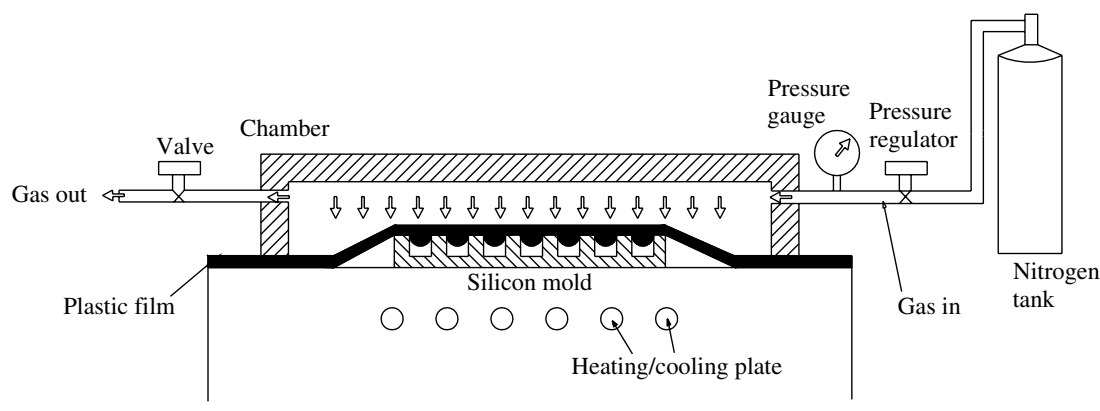

Fig. 2. Schematic showing the gas-assisted micro-hot-embossing machine. 


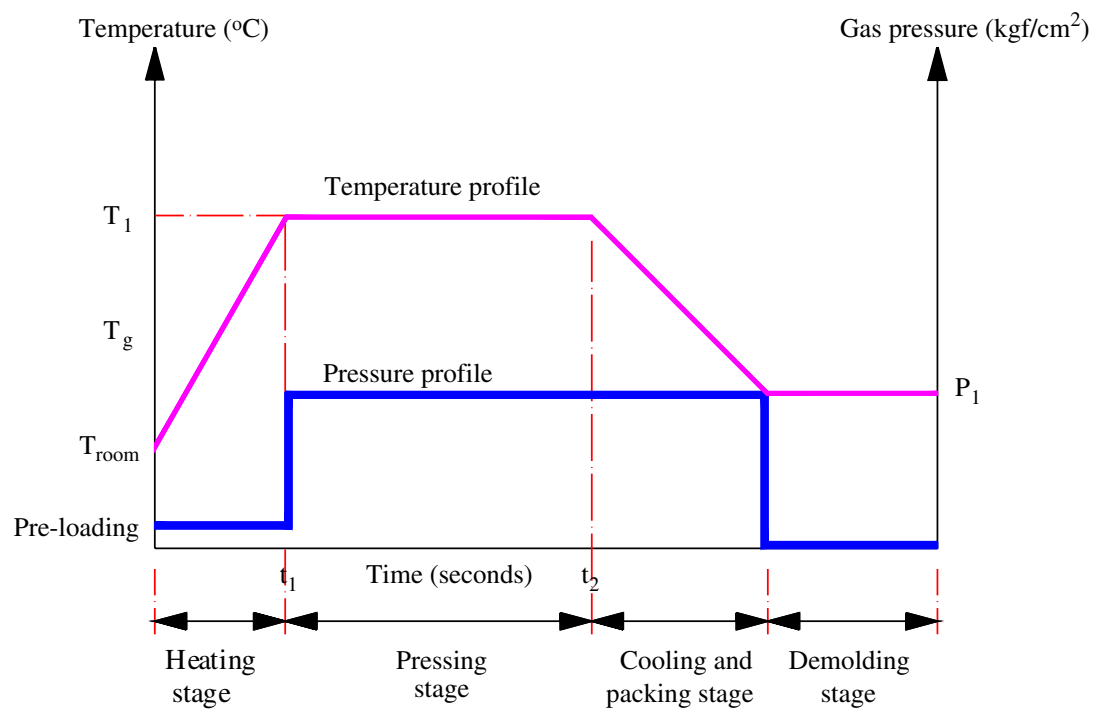

Fig. 3. Temperature, pressure and time profiles during gas-assisted micro-hot-embossing.

Finally, the stack is cooled down, the gas is vented, the chamber is opened, and the plastic film of microlens array is removed.

To verify the quality of microlens, the shape and height of embossed microlens are measured using surface profiler (Alpha-Step 500, TENCOR, USA) and inspected by scanning electron microscopy (JSM-5600, JEOL, Japan). Also, the surface roughness and optical property of plastic microlens array are measured and analyzed. This study further investigates the effects of heating temperature, gas pressure and pressing duration on the shape of formed microlens.

\section{Silicon mold of holes array}

The procedures for fabricating a silicon mold of holes array are shown in Fig. 1. The silicon mold with $300 \times 300$ holes array of $150 \mu \mathrm{m}$ in diameter,

Table 1

The processing conditions used in the experiments

\begin{tabular}{llll}
\hline \multicolumn{3}{l}{ Processing parameters } \\
\hline Run & $\begin{array}{l}\text { Processing } \\
\text { temperature }\left({ }^{\circ} \mathrm{C}\right)\end{array}$ & $\begin{array}{l}\text { Processing } \\
\text { pressure } \\
\left(\mathrm{kgf} / \mathrm{cm}^{2}\right)\end{array}$ & $\begin{array}{l}\text { Processing } \\
\text { time }(\mathrm{s})\end{array}$ \\
\hline 1 & 140 & 10 & 30 \\
2 & $\underline{150}$ & 20 & 60 \\
3 & 160 & $\underline{30}$ & 90 \\
4 & 170 & 40 & $\underline{120}$ \\
5 & 180 & 50 & 150 \\
\hline
\end{tabular}

Note. Reference parameters are underlined.
$200 \mu \mathrm{m}$ in pitch and $61.44 \mu \mathrm{m}$ in depth is fabricated by photolithography and deep reactive ion etching process described as follows.

The first step is conventional photolithography. The patterns on the mask are transferred onto the photoresist (PR) on top of the (100)-oriented silicon wafer (Fig. 1a). $\mathrm{SiO}_{2}$ layer was first thermally grown on top of the (100)-oriented silicon wafer. Then a $1.5 \mu \mathrm{m}$ thick AZ 5214 positive resist was

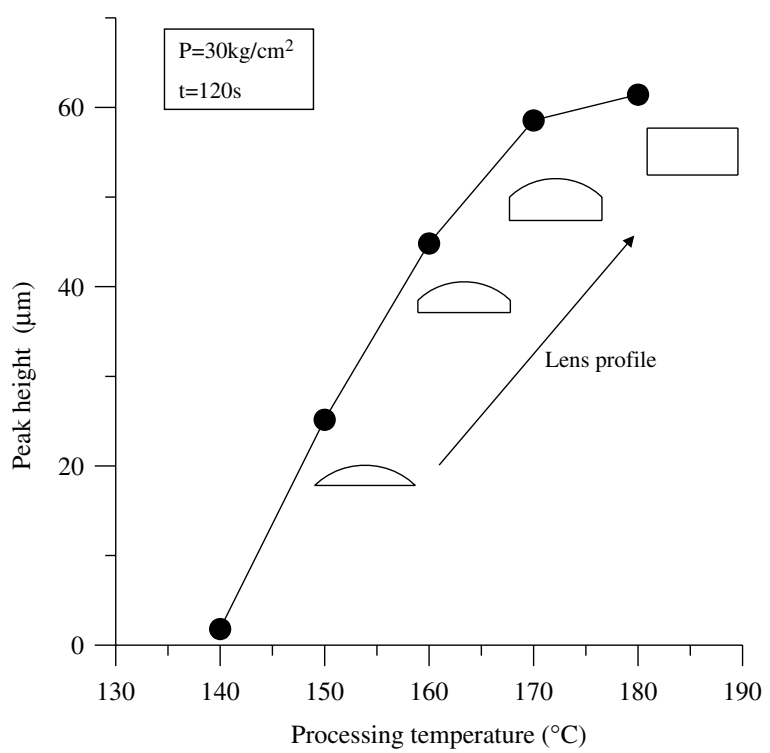

Fig. 4. Peak height of embossed microstructure for various processing temperature in the gas assisted micro-hot-embossing process. 
spun over the wafers at $4000 \mathrm{rpm}$ followed by a $100{ }^{\circ} \mathrm{C}$ softbake for $2 \mathrm{~min}$. The wafer was then exposed through a mask with circular holes feature for $10 \mathrm{~s}$. For this exposure, a UV Karl-Suss double side mask aligner was used. The aligner is equipped with ultra-violet wavelength $365-405 \mathrm{~nm}$. The UV intensity at $365 \mathrm{~nm}$ is $150 \mathrm{~mJ} / \mathrm{cm}^{2}$. The resists patterns were then developed using AZ $400 \mathrm{k}$ developer, diluted 1-4 with de-ionized water (DI), followed by a thorough rinse in DI. Following resist pattern definition, the wafers were baked at a tem- perature of $120^{\circ} \mathrm{C}$ in a oven for an additional $15 \mathrm{~min}$ in order to harden the resist structures. By hardening the resist, the feature patterns become less susceptible to degradation by ion bombardment during the reactive ion etching.

The second step is mask etching. Etching of silicon dioxide layer is done by selective reactive ion etching (RIE) to make the etching mask (Fig. 1b). The final step is anisotropic silicon etching and removal of the masking silicon dioxide layer (Fig. 1c). The silicon mold with holes array pattern

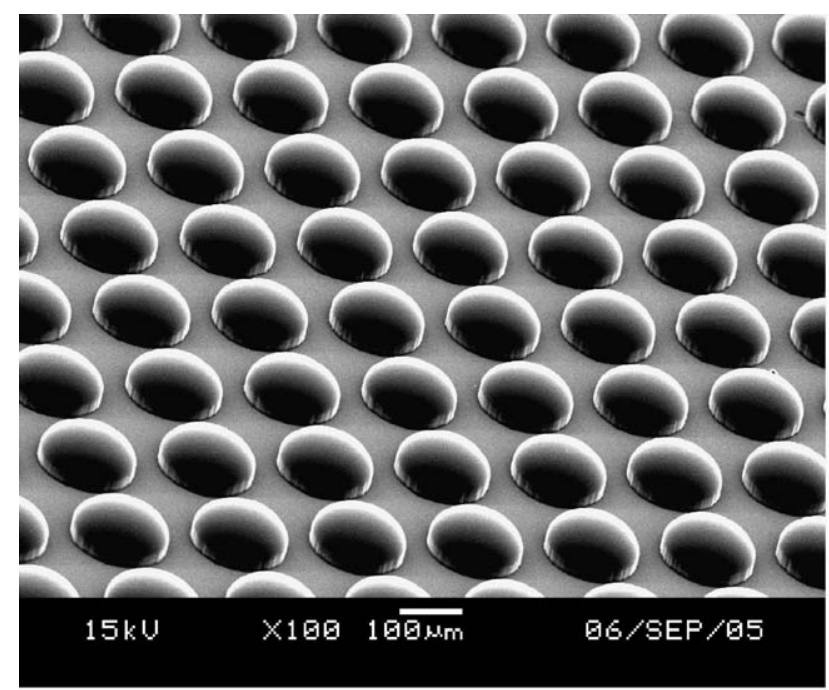

(a)

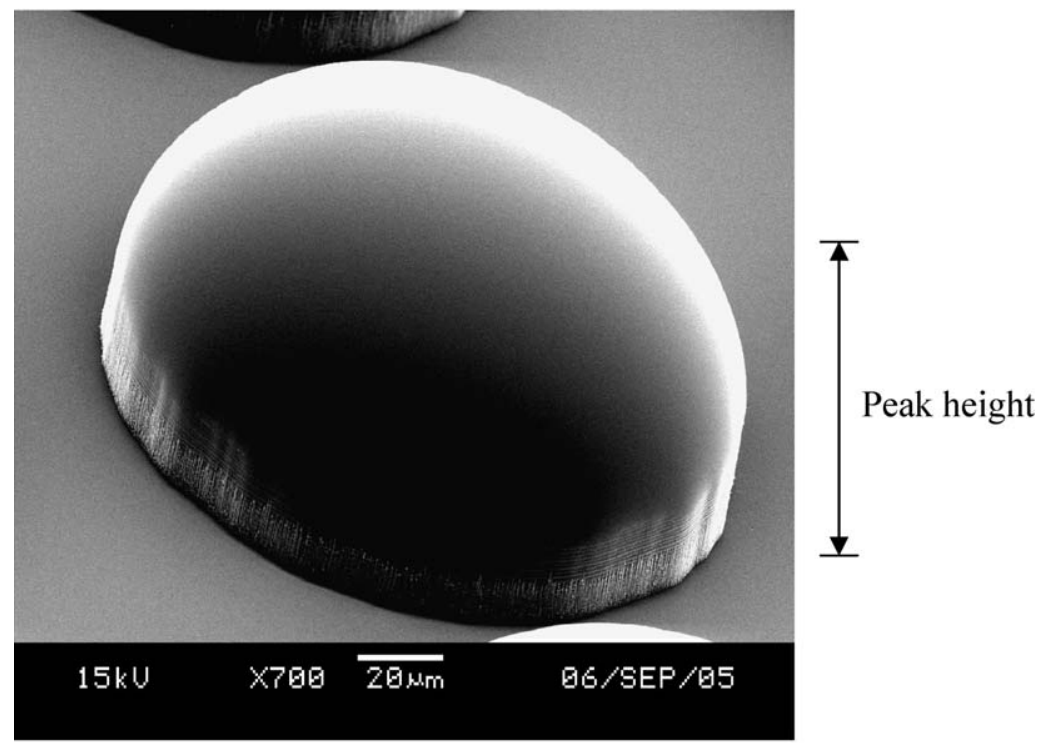

(b)

Fig. 5. SEM of the typical cylindrical microlens array. (a) The SEM image of a cylindrical microlens array and (b) the zoomed crosssection view of a single cylindrical microlens. 


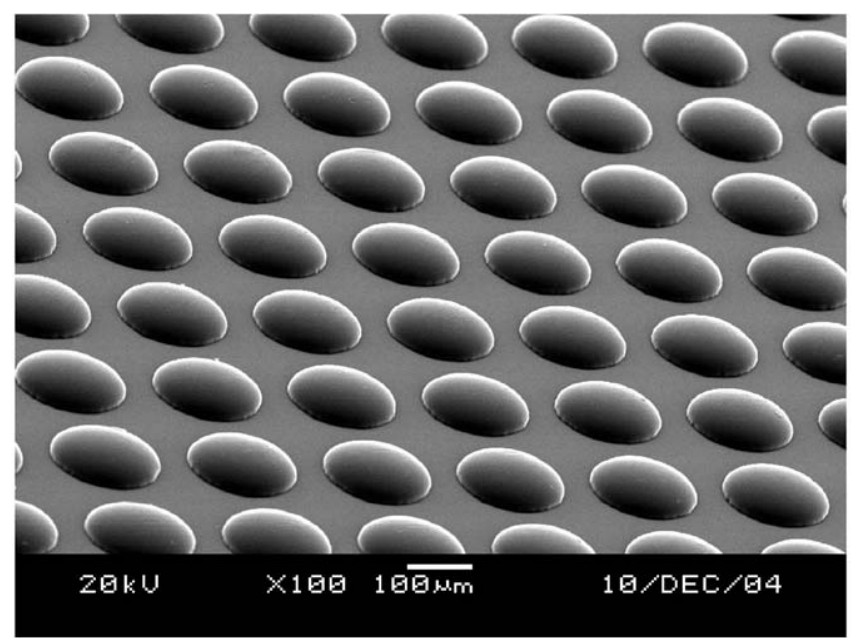

(a)
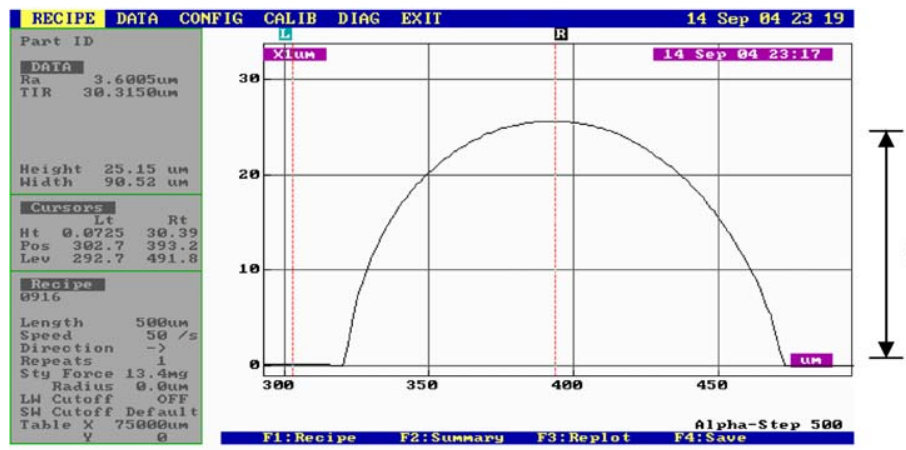

(b)

Fig. 6. The perfect hemispherical microlens array and its surface profile. (a) SEM image of the hemispherical microlens array and (b) surface profile of a single hemispherical microlens.

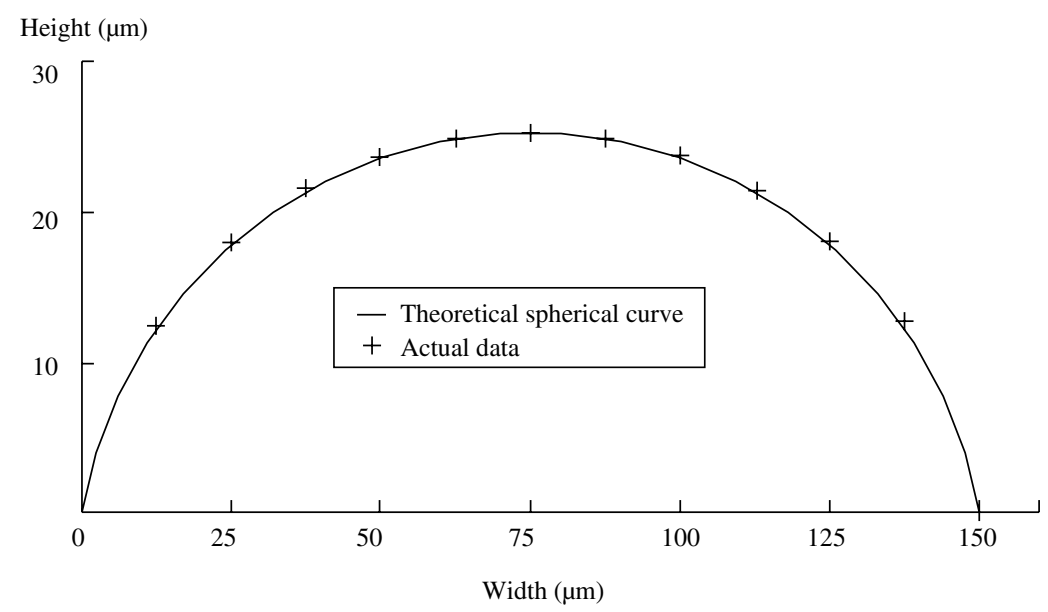

Fig. 7. Cross-sectional profile of a microlens compared with a perfect sphere curve.

is formed by deep reactive ion etching of silicon wafer. The etching rate was about $1.5 \mu \mathrm{m} / \mathrm{min}$, and the total processing time was about $41 \mathrm{~min}$. Each hole in the holes array is of diameter 
$150 \mu \mathrm{m}$, a pitch of $200 \mu \mathrm{m}$ and a depth of $61.44 \mu \mathrm{m}$. Fig. 1d shows a SEM image of the silicon mold and its surface profile scanned by the Alpha-step 500.

\section{The gas assisted micro-hot-embossing process}

After the silicon mold with holes array is made, gas-assisted micro-hot-embossing is used to fabricate the plastic microlens arrays. A film made of optical grade polycarbonate ( $\mathrm{PC}$, glass transition temperature $T_{\mathrm{g}} 130^{\circ} \mathrm{C}$, refractive index 1.59) is used as the substrate. The thickness of the PC film is $180 \mu \mathrm{m}$.

Fig. 2 shows the gas-assisted micro-hot-embossing system. The system is composed of a nitrogen tank $\left(120 \mathrm{kgf} / \mathrm{cm}^{2}\right.$ max.), a pressure regulator, valves, a stainless steel chamber and a heating/cooling plate. The gas pressure can be regulated with the pressure regulator. Electrical heating elements in the heating/cooling plate are used to heat the mold and plastic substrate, while water is used to cool the system. The mold can be a silicon wafer, glass, nickel mold, or other stamper with micro-features.

The four stages of the gas-assisted micro-hotembossing process as illustrated in Fig. 3 are explained as following:

(1) Heating stage: The plastic film/silicon mold stack is placed in a closed chamber and hot plate is heated to processing temperature

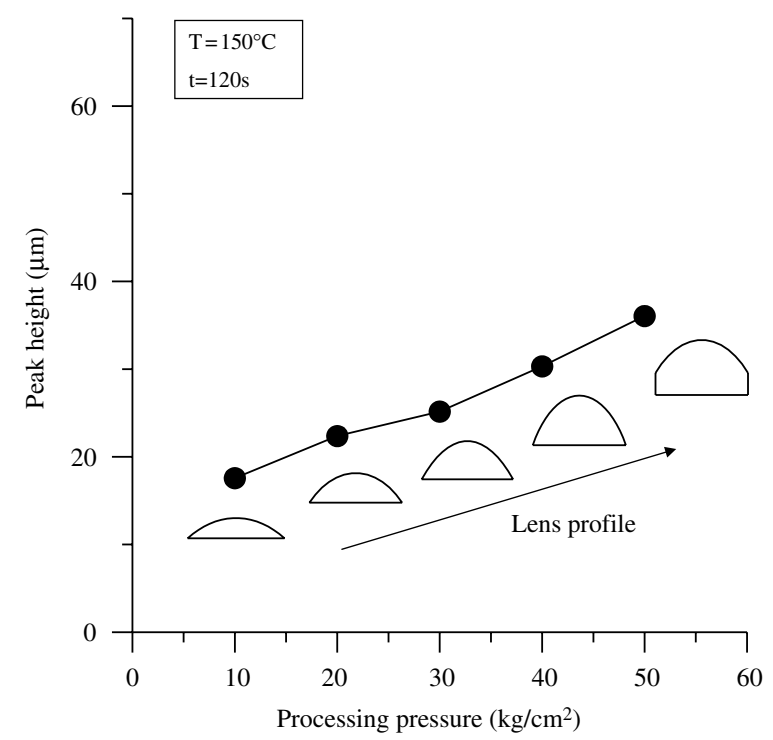

Fig. 8. Peak height of embossed microstructure increase with processing pressures in the gas-assisted micro-hot-embossing process.
( $\left.T_{1}\right)$ which is above the $T_{\mathrm{g}}$ of the plastic material. During the heating process, low gas pressure is applied to the film to prevent the film from creasing.

(2) Pressing stage: When the processing temperature is reached, the gas is introduced into the chamber to exert gas pressure $\left(P_{1}\right)$ over the film, forcing the film in close contact with the mold. Microlens will be formed in the holes.
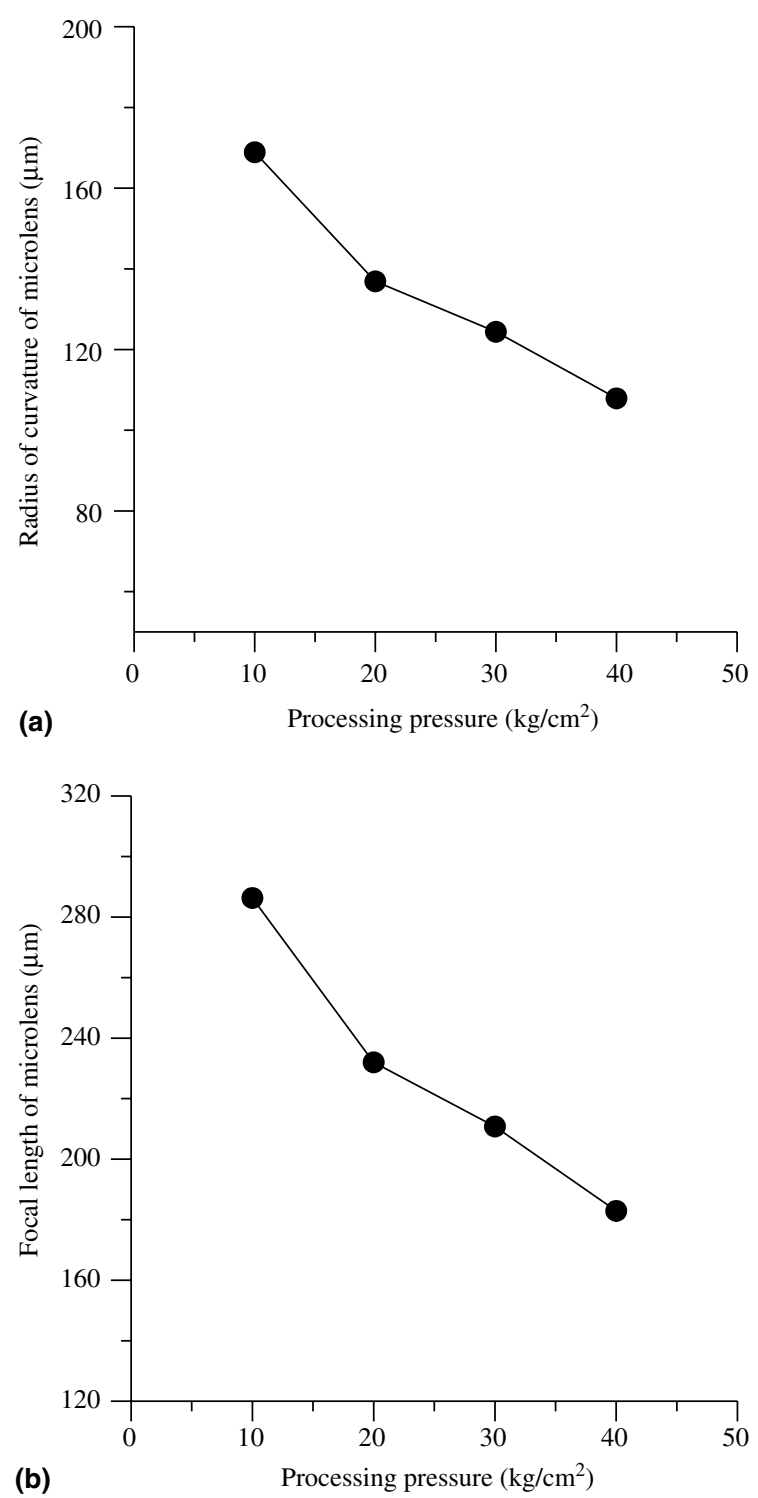

Fig. 9. Radius of curvature and focal length of microlens under various processing pressure in the process. The effect of processing pressure on (a) the radius of curvature of a microlens and (b) the focal length of a microlens. 
(3) Cooling and packing: After the processing time period $\left(t_{1}-t_{2}\right)$, the polymer is cooled down to below the glass transition temperature, while maintaining the pressure $\left(P_{1}\right)$ to prevent uncontrolled shrinkage and distortion.

(4) Demolding: At the de-molding temperature, the gas is vented, the chamber is opened, and the film with microlens array is removed.

\section{Processing conditions for microlens forming}

To study the effects of processing conditions on the surface profile of microlens, three processing parameters, i.e., the processing temperature, pressure, and time, were chosen. The values used in the experiments are listed in Table 1.

By changing one parameter, with other parameters fixed at reference states (underlined in Table 1), the effect of each parameter on the surface profile of microlens using gas-assisted micro-hot-embossing can be determined.

\subsection{Effects of temperature on the surface profile of microlens}

Fig. 4 shows the effect of processing temperature on the surface profile of microlens. With the processing pressure of $30 \mathrm{kgf} / \mathrm{cm}^{2}$ and time of $120 \mathrm{~s}$,

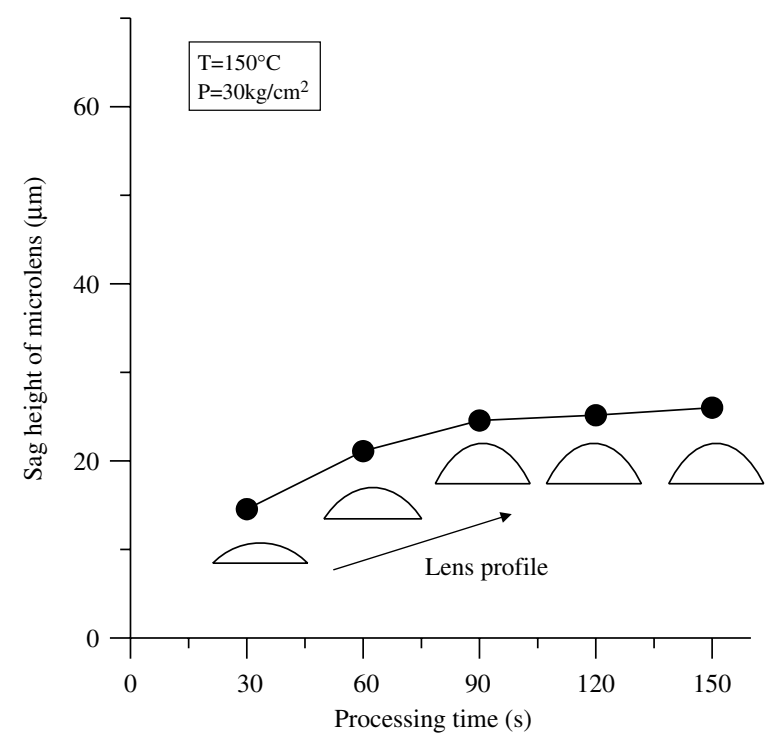

Fig. 10. Sag height of microlens increase with processing duration in the gas-assisted micro-hot-embossing process. when processing temperature increases from $140{ }^{\circ} \mathrm{C}$ to $180^{\circ} \mathrm{C}$, the peak height of the embossed microstructure is increases dramatically. The shape of the embossed microstructure changes from simple hemisphere to cylindrical hemisphere, and finally cylinder. When processing temperature is below or at $140{ }^{\circ} \mathrm{C}$, the plastic is too rigid and no lens shape is formed. On the other hand, when the temperature is above $150{ }^{\circ} \mathrm{C}$, the plastic is intruded into the hole and forms cylinder with or

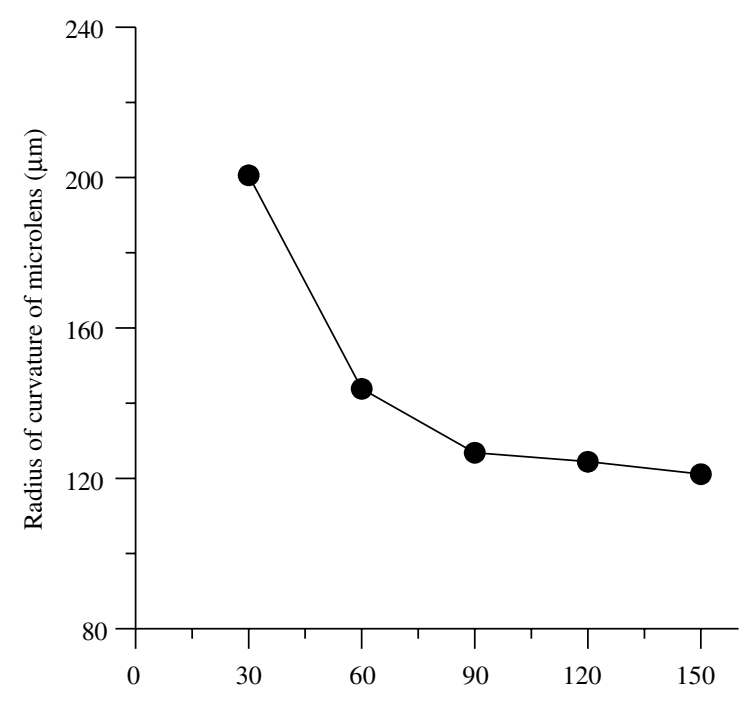

(a) Processing time (s)

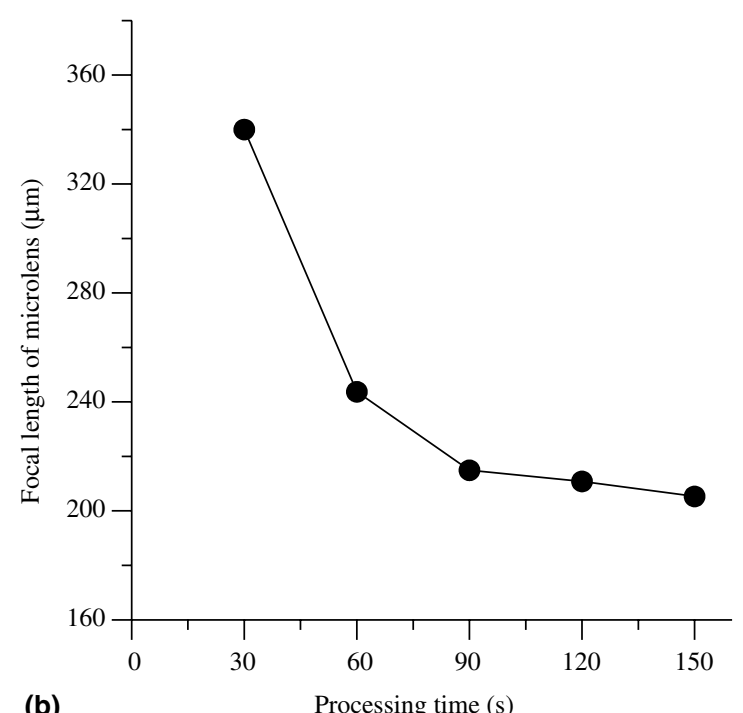

Fig. 11. Radius of curvature and focal length of microlens under various processing time in the process. The effect of processing time on (a) the radius of curvature of a microlens and (b) the focal length of a microlens. 
even without hemispherical profile on the top surface. Typical cylinders with hemispherical profile and its cross-sectional view are shown in Fig. 5.

Perfect hemispherical microlens on PC films can be formed at the processing temperature of $150{ }^{\circ} \mathrm{C}$, with pressure of $30 \mathrm{kgf} / \mathrm{cm}^{2}$ and duration of $120 \mathrm{~s}$. Fig. 6 shows a SEM image of the hemispherical microlens array and surface profile of a single microlens. A microlens in the lens array is of diameter $150 \mu \mathrm{m}$, a pitch of $200 \mu \mathrm{m}$ and a sag height of $25.15 \mu \mathrm{m}$. Fig. 7 shows its measured profile as compared to the theoretical spherical curve (solid line).

The radius of curvature $(R)$ and focal length $(f)$ of the microlens can be determined using equations based on the basic geometric and optical theory [9] as follows:

$R=\frac{D^{2}+4 h^{2}}{8 h}, \quad f=\frac{R}{n-1}$

where $D, h$ and $n$ are diameter, sag height of microlens and the refractive index of the PC material, respectively. The calculated radius of curvature and focal length of the present plastic microlens are $124.4 \mu \mathrm{m}$ and $210.8 \mu \mathrm{m}$, respectively.

\subsection{Effects of pressure on the surface profile of microlens}

Fig. 8 shows the effects on the surface profile of microlens when the processing pressure is changed from $10 \mathrm{kgf} / \mathrm{cm}^{2}$ to $50 \mathrm{kgf} / \mathrm{cm}^{2}$, with the temperature and duration maintained at $150{ }^{\circ} \mathrm{C}$ and $120 \mathrm{~s}$. When the gas pressure increases from $10 \mathrm{kgf} / \mathrm{cm}^{2}$ to $40 \mathrm{kgf} / \mathrm{cm}^{2}$, the sag height of microlens increases, and the radius of curvature and focal length decreases with the processing pressure as shown in Fig. 9. However, if the processing pressure is too high (beyond $50 \mathrm{kgf} / \mathrm{cm}^{2}$ ), cylinders with hemispherical profile on the top are resulted.

\subsection{Effects of duration on the surface profile of microlens}

Fig. 10 shows the effects of the pressing duration on the surface profile of microlens, with the pressure remained at $30 \mathrm{kgf} / \mathrm{cm}^{2}$ and temperature at $150{ }^{\circ} \mathrm{C}$. The sag height of the microlens increases with pressing duration, and the radius of curvature and focal length of the microlens decreased with the duration as shown in Fig. 11. Further increase of processing

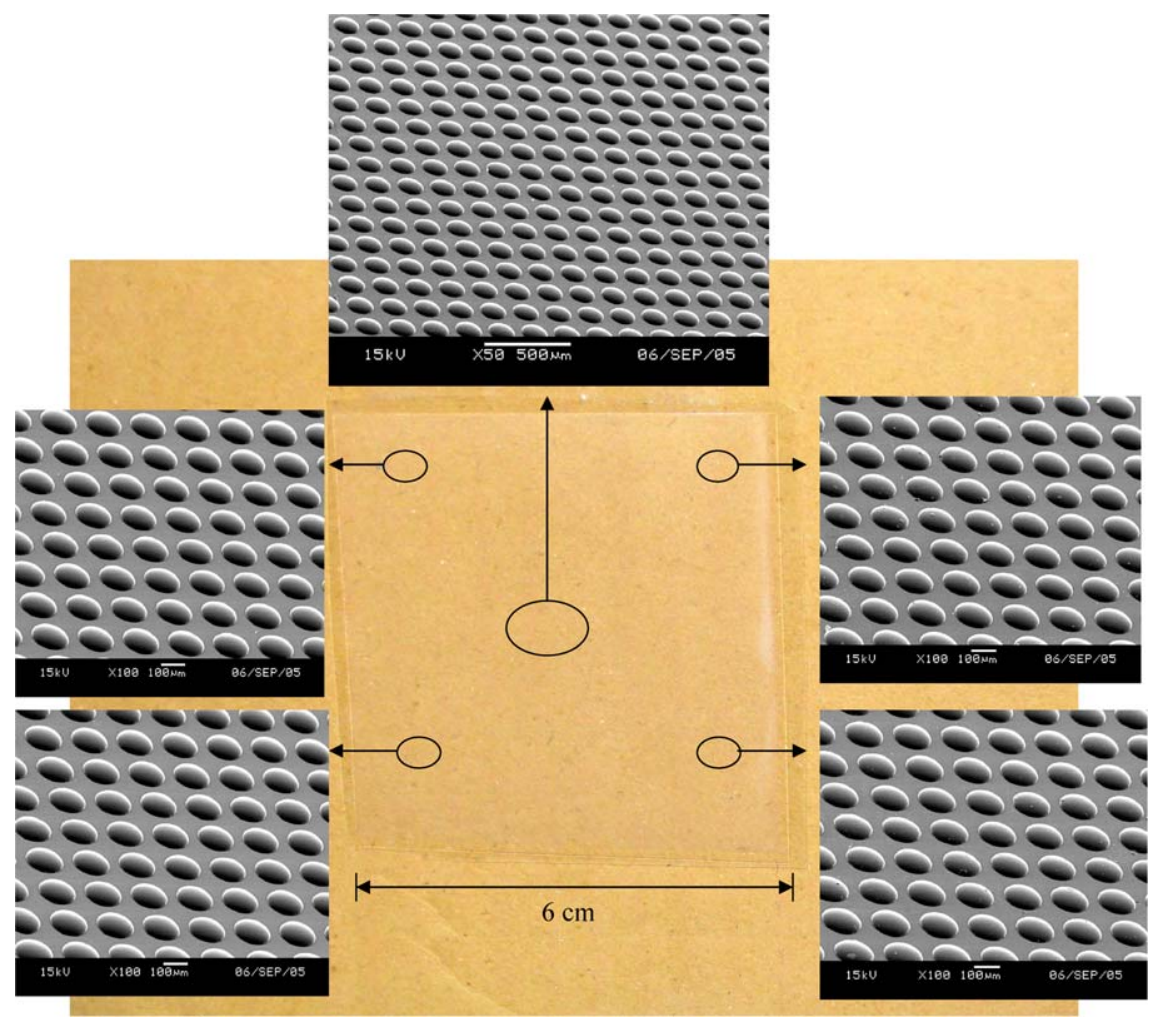

Fig. 12. The $300 \times 300$ array of plastic microlens fabricated using gas-assisted micro-hot-embossing process. 
duration beyond $90 \mathrm{~s}$ results in very small increase in the sag height of microlens.

Based on the above study, the processing temperature and pressure are the two most critical processing parameters in gas-assisted micro-hot-embossing process. At the temperature of $150{ }^{\circ} \mathrm{C}$ (for $\mathrm{PC}$ material), when the gas pressure is between 10 and $40 \mathrm{kgf} / \mathrm{cm}^{2}$, microlens of increased sag heights can be formed. The increase in pressing duration also results in increase in sag height.

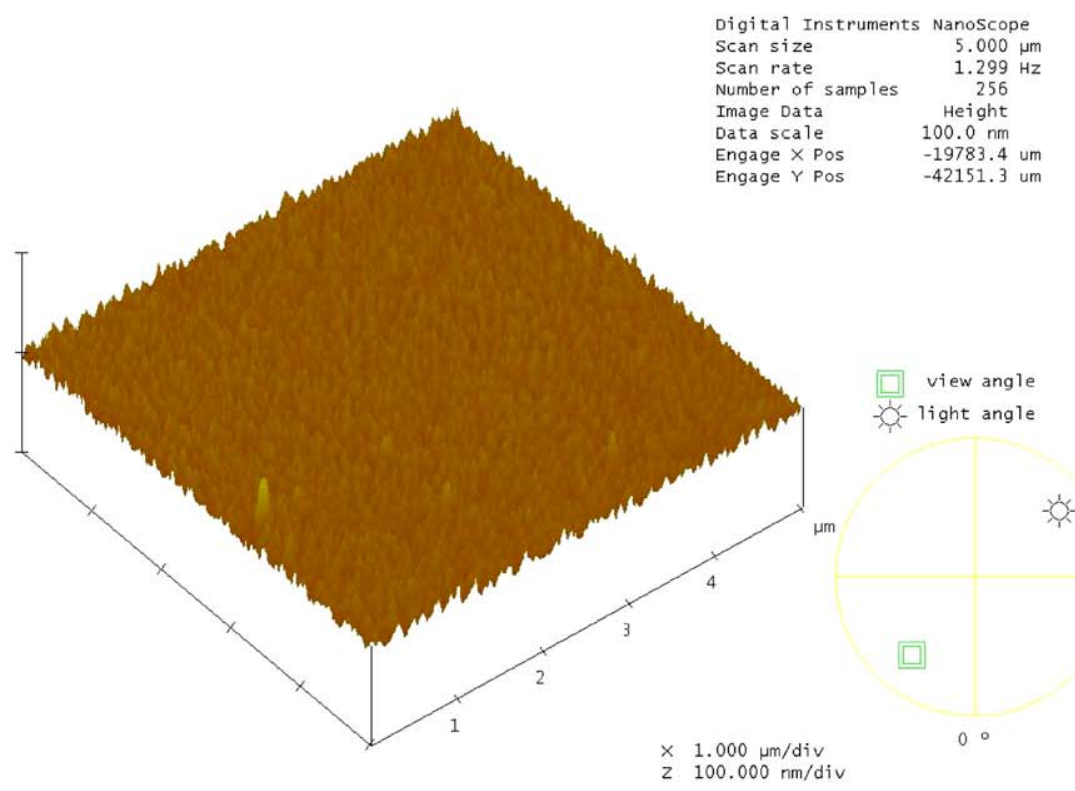

20050819-microlensa. 002

$$
\text { Peak }
$$
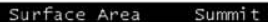

Zero Crossing

Roughness Analysis

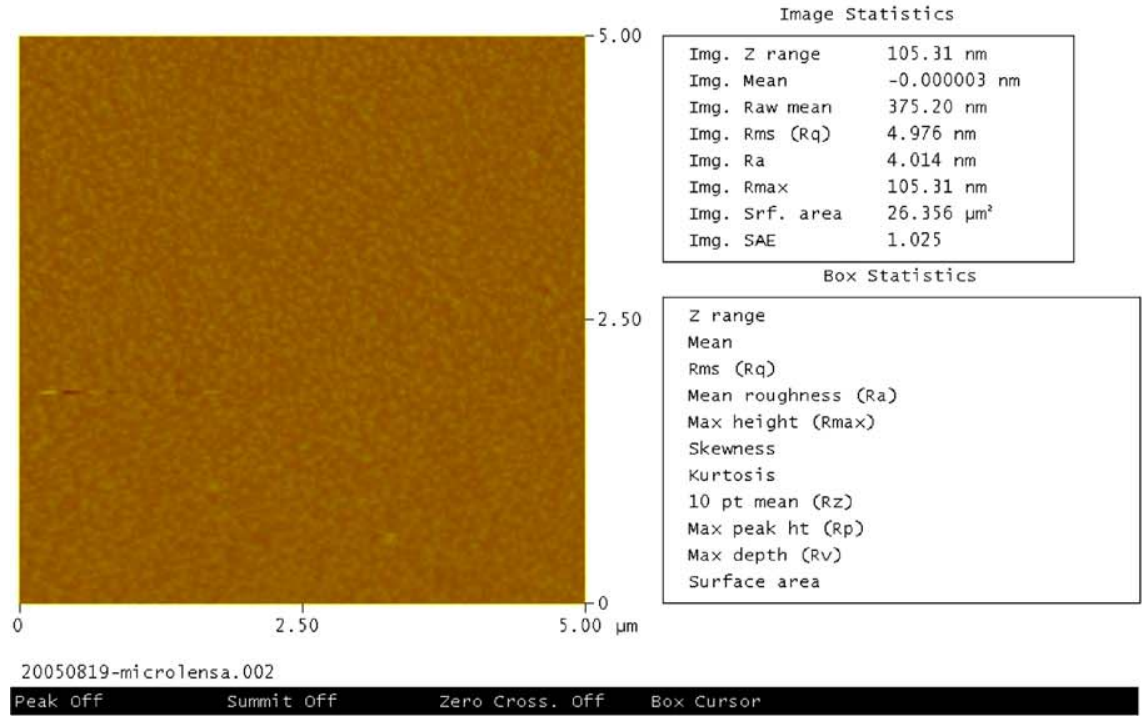

Fig. 13. AFM image and surface roughness of a plastic microlens. 


\section{The surface quality and optical property of plastic microlens}

Fig. 12 shows a plastic film with $300 \times 300$ microlens array fabricated using gas-assisted micro-hotembossing process, under the condition of $150{ }^{\circ} \mathrm{C}$, $30 \mathrm{kgf} / \mathrm{cm}^{2}$ and $120 \mathrm{~s}$. It is observed that array of microlens were successfully fabricated over the whole plastic film.

In order to characterize the surface morphology of the plastic microlens array, the surface roughness was measured by atomic force microscope (DIMENTION 3100, Digital Instrument, USA). Fig. 13 shows the AFM image and roughness analysis of a randomly picked microlens. The averaged surface roughness $(\mathrm{Ra})$ of microlens is $4.014 \mathrm{~nm}$ over an area of $5 \mu \mathrm{m}$ by $5 \mu \mathrm{m}$ on the top surface of microlens.

The focused light spot was measured by a beam profiler, consisting of expanding lenses, filter and CCD system using a $665 \mathrm{~nm}$ laser light source. Fig. 14 shows the setup and a portion of the spot pattern produced by a plastic microlens array. The image shows the uniform and intensive focusing function of the microlens array.

\section{Conclusions}

In this paper, we proposed a novel fabrication method of plastic microlens array using gas-assisted micro-hot-embossing process with a silicon holes array mold. A large array of $300 \times 300$ plastic microlens with diameter of $150 \mu \mathrm{m}$ and pitch of $200 \mu \mathrm{m}$ has been successfully produced. The experimental results show that the shape and height of embossed microlens depend on processing temperature, pressure and duration. The peak height of embossed microlens increases significantly with the increase in processing temperature and pressure. For PC microlens fabrication, the optimal processing temperature is $150{ }^{\circ} \mathrm{C}$, the optimal pressure is $10-40 \mathrm{kgf} / \mathrm{cm}^{2}$ and the optimal processing duration is $30-90 \mathrm{~s}$. Microlens of different curvatures and focal lengths can be obtained with a proper combination of pressure and duration. The measured surface roughness of a plastic microlens formed is $4.014 \mathrm{~nm}$ and the focused

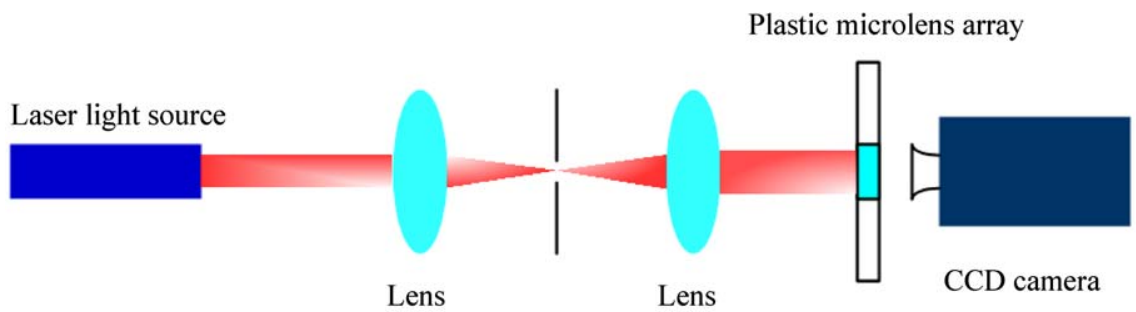

(a)

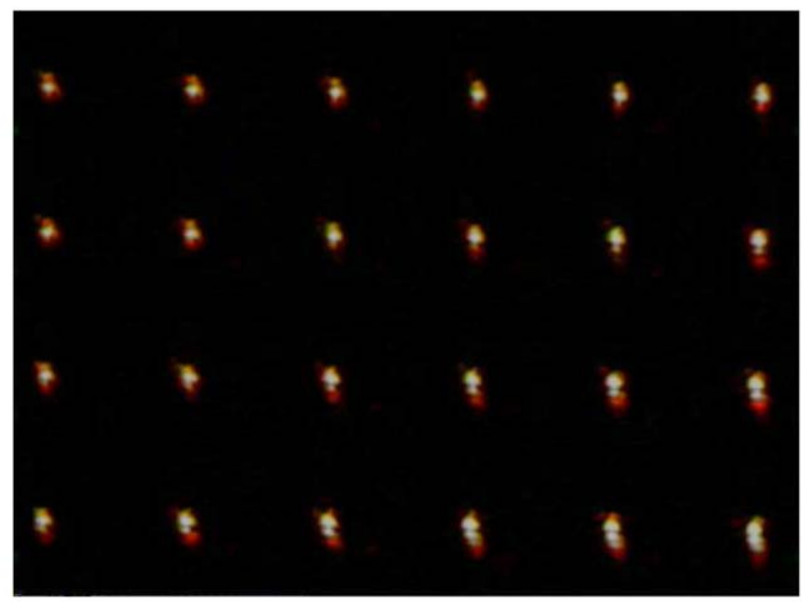

(b)

Fig. 14. Optical experimental setup and a light spot pattern produced by a plastic microlens array. (a) Schematic of the optical experimental setup and (b) light spot image. 
light spot through the microlens array is uniform and intensive. This study demonstrates the great potential of the gas-assisted micro-hot-embossing process with a silicon holes array mold for efficient production of microlens arrays.

\section{Acknowledgements}

This work was partially supported by the National Science Council (Series No. NSC93-2218-E002-019) of Taiwan. The experimental work was carried out at the MEMS Laboratory in the Nano-Electro-Mechanical-Systems Research Center at NTU is acknowledged.

\section{References}

[1] D. Daly, R.F. Stevens, M.C. Hutley, et al., Meas. Sci. Technol. 1 (1990) 759.

[2] M. He, X.C. Yuan, N.Q. Ngo, et al., Opt. Lett. 28 (2003) 731.

[3] C.P. Lin, H. Yang, C.K. Chao, J. Micromech. Microeng. 13 (2003) 775.

[4] S. Mihailov, S. Lazare, Appl. Opt. 32 (1993) 6211.

[5] Q. Peng, Y. Guo, S. Liu, Opt. Lett. 27 (2002) 1720

[6] D.L. MacFarlane, V. Narayan, J.A. Tatum, et al., IEEE Photon. Technol. Lett. 6 (1994) 1112.

[7] N.S. Ong, Y.H. Koh, Y.Q. Fu, Microelectron. Eng. 60 (2000) 365.

[8] L.W. Pan, X. Shen, L. Lin, J. Micromech. Microeng. 13 (2004) 1063.

[9] S. Sinzinger, J. Jahns, Microoptics, Wiley-VCH, Weinheim, 1999. 